\title{
Addressing cost-related barriers to prescription drug use in Canada
}

\author{
Karen L. Tang MD, William A. Ghali MD MPH, Braden J. Manns MD MSc
}

Competing interests: None declared.

This article has been peer reviewed.

Correspondence to: Braden J. Manns, braden.manns@albertahealth services.ca

CMAJ 2014. DOI:10.1503 /cmaj.121637
I $\mathrm{n}$ a recent randomized trial, Choudhry and colleagues $^{1}$ showed that patients randomly assigned to receive full insurance coverage of their medications prescribed after myocardial infarction had lower rates of major vascular events and improved adherence compared with patients who had copayments. These findings have heightened the awareness of the potential negative impact of patient-borne expenses for prescription drugs on treatment access and outcomes. This concern was raised at the Canadian Medical Association's 2012 annual general meeting, which addressed the issue of health inequities. ${ }^{2}$ The issue is particularly relevant in Canada, because prescription drugs are not considered "essential" therapy under medicare and therefore are not covered for many patients. In this article, we examine drug expenses as a barrier to outpatient prescription medications and the consequences of this from the patient's perspective. We discuss the multiple players who influence patient-related drug expenses and suggest changes to minimize inequity in drug access.

\section{Drug expenses are a barrier to appropriate therapy}

In Canada, drug expenses are borne by patients, publicly funded provincial/territorial or federal drug plans and private insurers. Cost-related nonadherence is an important issue, reported by $9.6 \%$ of the respondents to the 2007 Canada Community Health Survey who received a prescription and by $20.4 \%$ of respondents from low-income

\section{- KeY POINTS}

- Patient-borne drug expenses are an important barrier to outpatient prescription medications.

- Drug coverage varies widely across Canadian provinces and territories, which results in inequity in drug access.

- Governments and prescribers can each influence patients' out-ofpocket drug expenses.

- Physicians should have a broad understanding of medication prices so that they can prescribe clinically effective, yet affordable and costeffective medications. households. ${ }^{3}$ In a survey of Canadians who had one or more of hypertension, diabetes or cardiovascular disease, $14 \%$ reported having no drug insurance. ${ }^{4}$ Even those with insurance may face difficulty affording medications, because most systems require copayments in part to lower expenses for the insurer. After copayments were introduced in the province of Quebec, the number of prescription drugs used per day decreased by $9 \%$ among older people and by $16 \%$ among those receiving social assistance; these reductions were associated with an increased rate of emergency department visits by 14.2 and 54.2 events per 10000 person-months respectively. ${ }^{5}$

\section{Who influences drug prices?}

\section{Federal government}

The control of prescription drug prices starts with the federal government and the independent body it established in 1987 - the Patented Medicine Prices Review Board of Canada. The board regulates prices of prescription and nonprescription patented drugs to ensure that they are not excessive. It does this by comparing a drug's price with the price at which it is sold in seven selected Organisation of Economic Co-operation and Development (OECD) countries (France, Germany, Italy, Sweden, Switzerland, the United Kingdom and the United States). In addition, a comparison is made with the prices at which other medicines in the same therapeutic class have been sold in the relevant Canadian market.

Although a reasonable first step in attempting to establish uniformity of Canadian patented drug prices and fairness on an international scale, the board's influence has been somewhat limited. First, the seven comparator countries have generally high medication prices, with 4 of them having the highest medication prices worldwide. ${ }^{6}$ Second, the Patented Medicine Prices Review Board does not regulate prices of generic drugs. Among the seven comparator countries, France and Britain's generic drug prices are $71 \%$ and $81 \%$, respectively, relative to those in Canada, ${ }^{6}$ and only Switzerland has higher generic prices than Canada. 


\section{Provincial/territorial governments}

\section{Drug formularies}

Provincial and territorial governments in Canada have a direct influence on the provision of prescription drugs by establishing drug formularies, negotiating drug prices and legislating price ceilings for generic drugs. Within provincial/territorial drug plans, they also establish eligibility criteria and copayment levels, all factors that influence patients' out-of-pocket expenses.

Although provinces and territories have generous plans for residents receiving social assistance, where drug coverage is offered with low or no copayments, the "working poor" may not have the same benefits. In an analysis of the extent of drug coverage in Canada, Kapur and Basu found that households with an annual income of \$10 000-\$29 999 were 14\%-31\% less likely than those with an annual income of \$30 000-\$39 999 to have drug coverage. ${ }^{8}$ Demers and colleagues found wide variations in provincial drug plans across Canada. ${ }^{9}$ A single woman with an annual income of $\$ 14000$ requiring only two prescription drugs, levothyroxine and atorvastatin, would pay anywhere from $\$ 252$ annually in British Columbia to more than $\$ 800$ in New Brunswick. ${ }^{910}$

\section{Generic and therapeutic substitutions}

Most provincial and territorial governments provide incentives to use generic drugs. Benefit plans reimburse only the cost of generic alternatives. If the brand-name drug is desired, then the patient must pay the difference. British Columbia also allows for therapeutic substitutions, under a policy known as reference drug pricing. Within each group of medications deemed therapeutically interchangeable, only the price of the least expensive medication, or the "reference drug," is reimbursed. Despite initial concerns that this policy would result in a switch to less effective medications and increased noncompliance, a 2006 Cochrane review found no increase in adverse events or health care utilization. ${ }^{11}$ However, the program has not expanded beyond the initial five medication classes owing to lobbying by the pharmaceutical industry, inconsistent evidence of sustainable health care savings and electoral politics. ${ }^{12}$ Although policies for generic and therapeutic substitutions were created to decrease health care spending at a population level, they also result in lower out-of-pocket expenses for patients because less expensive drugs are favoured.

\section{Generic-drug pricing}

Provinces and territories have been actively trying to reduce generic drug prices. In 2010, Ontario mandated that generic drug prices be set at no higher than $25 \%$ of the brand-name drug price. British Columbia and Alberta soon followed, by changing the maximum generic-drug price to $35 \%$ and $45 \%$ of the brand-name price, respectively. ${ }^{13,14}$ A promising development is collaboration among provinces and territories to collectively bulk buy generic medications to enhance bargaining power. As of April 2013, this has lowered the price of six generic drugs to $18 \%$ of the brand-name price. ${ }^{15}$

There have been concerns that excessive price controls may limit entry of new generic drugs to the market, if the retail price is below the cost of production, ${ }^{13}$ or result in drug shortages, as has been recently seen with the cancer drug cytarabine. ${ }^{16}$ These potential negative impacts must be weighed against the benefits of lowering provincial/territorial and individual expenses.

\section{Limitations in bargaining power}

Although drug purchasing and price negotiations with manufacturers are within the provincial/ territorial jurisdiction, bargaining power is limited. Each jurisdiction is a relatively small market, and one jurisdiction's negotiations with drug manufacturers may undermine another's bargaining ability. For example, Quebec has legislated that, for generic drugs, a medication's sale price to its public drug plan must be lower than that paid by other provinces. This has created a price floor, whereby manufacturers are reluctant to offer other provinces lower prices than those in Quebec. ${ }^{6}$

\section{Physicians}

Physicians influence drug prices by not prescribing cost-effective medications. Physicians have a responsibility to be aware of the prices of the medications they prescribe. However, in a survey of 134 clinicians in an urban primary care centre, $80 \%$ stated they often felt unaware of the actual costs. ${ }^{17}$ In addition, a systematic review indicated that physicians consistently overestimated the cost of inexpensive drugs and underestimated the cost of more expensive ones. ${ }^{18}$

One example of the importance of knowing medication prices is in the treatment of heart failure. Current treatment guidelines recommend using one of the three $\beta$-blockers proven to reduce mortality (bisoprolol, carvedilol or sustainedrelease metoprolol succinate) in patients with systolic heart failure, without explicit guidance as to which $\beta$-blocker to use. ${ }^{19}$ Physicians may not recognize that, despite similarities in clinical efficacy, carvedilol ( $\$ 1.51$ per day for $25 \mathrm{mg}$ twice daily) is more than 3 times the cost of metoprolol $(\$ 0.44$ per day for $100 \mathrm{mg}$ twice daily). ${ }^{20}$

Another barrier is suboptimal physicianpatient communication. In surveys of 133 gen- 
Table 1: Barriers and proposed solutions to improve patient access to prescription drugs, and their anticipated effect on government expenses

\begin{tabular}{|c|c|c|c|}
\hline Players & Current barriers to drug access & Currently active and proposed solutions & $\begin{array}{l}\text { Anticipated immediate effect } \\
\text { on government expenses }\end{array}$ \\
\hline \multirow[t]{2}{*}{$\begin{array}{l}\text { Federal } \\
\text { government }\end{array}$} & $\begin{array}{l}\text { Patented Medicine Prices Review } \\
\text { Board regulates prices of patented } \\
\text { drugs in Canada by comparing them } \\
\text { with the prices at which they are sold } \\
\text { in } 7 \text { comparator OECD countries (some } \\
\text { of which have the highest drug prices } \\
\text { worldwide) and with the prices of } \\
\text { other medicines in the same } \\
\text { therapeutic class sold in the relevant } \\
\text { Canadian market }^{6}\end{array}$ & $\begin{array}{l}\text { Change the comparator countries to } \\
\text { include all OECD countries, or select a } \\
\text { group of more diverse countries to better } \\
\text { reflect true international market drug } \\
\text { prices }^{6}\end{array}$ & Decrease \\
\hline & No regulation of generic drug prices & $\begin{array}{l}\text { Individual provinces and territories have } \\
\text { taken on this role }{ }^{13,14} \text { by setting maximum } \\
\text { generic prices at a percentage of the } \\
\text { brand-name drug price }\end{array}$ & Decrease \\
\hline \multirow[t]{4}{*}{$\begin{array}{l}\text { Provincial/ } \\
\text { territorial } \\
\text { governments }\end{array}$} & \multirow{2}{*}{$\begin{array}{l}\text { Limited negotiation with } \\
\text { pharmaceutical companies to lower } \\
\text { prices of generic and brand-name } \\
\text { drugs }\end{array}$} & $\begin{array}{l}\text { In } 2012 \text {, the premiers committed to work } \\
\text { together to bulk buy generic drugs to } \\
\text { enhance collective bargaining power }{ }^{15}\end{array}$ & Decrease \\
\hline & & $\begin{array}{l}\text { Alternatively, a national drug agency, } \\
\text { with a single formulary, could negotiate } \\
\text { drug prices more effectively }\end{array}$ & $\begin{array}{l}\text { Overall decrease to both } \\
\text { levels of government, but } \\
\text { costs may shift to the federal } \\
\text { level }\end{array}$ \\
\hline & $\begin{array}{l}\text { Variation in provincial/territorial drug } \\
\text { plans and formularies, leading to } \\
\text { inequity in drug access }\end{array}$ & $\begin{array}{l}\text { Create a national drug agency, universal } \\
\text { drug plan and single formulary }\end{array}$ & $\begin{array}{l}\text { Increase, especially at federal } \\
\text { level }\end{array}$ \\
\hline & $\begin{array}{l}\text { Variation in drug coverage for the } \\
\text { working poor, whose copayment } \\
\text { levels are high relative to their income }\end{array}$ & $\begin{array}{l}\text { Implement different copayment systems: } \\
\text { - People with lower incomes could have } \\
\text { lower copayments than those with } \\
\text { higher incomes }\end{array}$ & Increase \\
\hline \multirow[t]{2}{*}{ Physicians } & $\begin{array}{l}\text { Lack of knowledge about drug } \\
\text { prices }^{18,24}\end{array}$ & $\begin{array}{l}\text { Improve physician knowledge of drug } \\
\text { prices: } \\
\text { - Provide price information in the form } \\
\text { of a manual, }{ }^{25} \text { prescription template }{ }^{26} \\
\text { or electronic prescribing system }{ }^{27} \\
\text { - Provide frequent feedback and } \\
\text { reminders to be conscious of drug } \\
\text { costs }^{25,28} \\
\text { - Encourage "step-up therapy": if } \\
\text { different drugs have comparable clinical } \\
\text { effectiveness, start with the least costly } \\
\text { one }\end{array}$ & $\begin{array}{l}\text { Uncertain, although the costs } \\
\text { of an effective educational } \\
\text { intervention could be offset } \\
\text { by cost savings in drug } \\
\text { expenses }\end{array}$ \\
\hline & $\begin{array}{l}\text { No routine physician-patient } \\
\text { communication on the financial } \\
\text { impact of prescribed medications }{ }^{22}\end{array}$ & $\begin{array}{l}\text { Improve communication: } \\
\text { - Increase awareness that drug expenses } \\
\text { are an important barrier to access } \\
\text { and that patients want to discuss this } \\
\text { issue }{ }^{22} \\
\text { - Provide easily accessible information on } \\
\text { drug prices to physicians, as a reminder } \\
\text { of the financial impact of patient-borne } \\
\text { expenses }\end{array}$ & $\begin{array}{l}\text { Uncertain, although the costs } \\
\text { of an effective intervention } \\
\text { to improve communication } \\
\text { could be offset by cost } \\
\text { savings in drug expenses }\end{array}$ \\
\hline
\end{tabular}


eral internists and 484 of their patients, $85 \%$ of the patients said they had never discussed the impact of drug prices with their doctor before receiving medications, despite a majority of patients indicating their wish to have such a conversation. ${ }^{21}$ Barriers included lack of time and physician perception of patient discomfort. ${ }^{22}$

\section{What are possible solutions?}

Given the complexity of the problem, it is not surprising that improving drug affordability will require addressing several barriers at different levels. Table 1 summarizes the barriers at the federal, provincial/territorial and physician level, some proposed solutions and their likely impact on the government payer.

\section{Change the Patented Medicine Prices Review Board's processes}

Because the Patented Medicine Prices Review Board currently regulates prices of patented drugs relative to prices in countries with some of the highest drug prices worldwide, a simple change in the comparator countries used could result in lower prices in Canada. ${ }^{6}$ The role of this agency could also be expanded to regulate prices of generic drugs.

\section{Create a national drug agency and program}

The problems with current provincial/territorial drug plans and their inequities have long been recognized. The 1997 National Forum on Health, the 2002 Kirby Report and the 2002 Romanow Report $^{29,30}$ all proposed the creation of a national drug agency to minimize disparity in drug coverage among provinces. Also, given the larger market, a single national drug agency would be more effective than individual provinces and territories in negotiating drug prices with pharmaceutical companies. France, Britain, Australia and New Zealand all have national pharmacare; their average prices of patented drugs range from $76 \%$ to $90 \%$, and generic drugs from $23 \%$ to $83 \%$, of the prices in Canada. ${ }^{6}$

A national drug agency would be well positioned to implement a universal drug program, where all Canadians would have access to some type of drug coverage. We acknowledge many barriers to a national drug plan. First among these is the upfront cost from increased use of prescription drugs, a volume effect estimated to be $10 \% .{ }^{6}$ The government would also then be the single payer, rather than sharing expenditures with the private sector as it currently does at a 70\%/30\% split. ${ }^{31}$ However, concurrent changes such as elimination of private drug plans and their generous tax subsidies could result in improved efficiency of health care spending and an estimated net savings of $\$ 2.95$ billion. ${ }^{6}$ There would be additional challenges, including the need to redefine federal and provincial/territorial roles in health care. Finally, some provinces and territories may have different views regarding which medications should be covered and to what extent; under a single drug plan, these different views could be accommodated by having a national minimum formulary that could be enhanced at a provincial/territorial level.

\section{Change copayment systems}

There are many methods of changing copayment systems to improve drug access. Table 1 highlights possible changes, including differential copayments based either on low income or on the clinical value of a medication. These proposed changes are different from the tiered copayment system commonly seen in the US, where tiers are set based on medication acquisition cost alone rather than on ability to pay or clinical value. The randomized controlled trial by Choudhry and colleagues of the effect of full coverage for preventive medications after myocardial infarction ${ }^{1}$ is an example of establishing the level of cost sharing based on a drug's clinical benefit. Given that certain drugs are of high value, the intervention group had copayments waived, which resulted in better medication adherence $(4 \%-6 \%$ points higher) than in the group who had copayments. Generalizability of these findings to other conditions requires further evaluation.

\section{Educate physicians about drug-related expenses}

To better educate physicians, multiple strategies have been used. Academic detailing, ${ }^{25}$ provision of easily accessible price information ${ }^{26}$ implementation of a computerized prescribing system and integration of price information with evidencebased recommendations ${ }^{27}$ have all been shown to lower medication expenses. Providing price information decreases patient-borne drug expenses by closing the gap in physician's knowledge of drug prices and by improving physician-patient communication in this area. ${ }^{22}$ Further information on the cost-effectiveness of these proposed interventions is required to inform policy.

Educating physicians on drug prices may be even more effective if the information were juxtaposed with information on drug efficacy. For example, tricyclic antidepressants and gabapentin are both effective in treating neuropathic pain. ${ }^{32,33}$ Gabapentin has not been shown to be superior, and it is 10 times more costly than tricyclic antidepressants. If physicians were aware 
that similarly effective medications had vastly different prices, they may be more likely to start with a less expensive one first.

\section{Conclusion}

Patient-borne expenses for prescription drugs are an important issue and can have a negative impact on treatment access and outcomes. Without better drug coverage systems, Canadians do not have universal health coverage. As the 2012 Canadian Medical Association meeting so clearly delineated, physicians have a responsibility in championing equality of access to care. ${ }^{2}$ Individually, physicians may be limited in their ability to create changes at the national and provincial/territorial levels, but they can do their part by gaining familiarity with drug prices to increase their awareness of the financial impact of their prescribing choices on patients.

\section{References}

1. Choudhry NK, Avorn J, Glynn RJ, et al. Full coverage for preventive medications after myocardial infarction. N Engl J Med 2011; 365:2088-97.

2. Kondro W. The fiendish puzzle of health inequities. CMAJ 2012; 184:1456-7

3. Law MR, Cheng L, Dhalla IA, et al. The effect of cost on adherence to prescription medications in Canada. CMAJ 2012;184: 297-302.

4. Barriers to care for people with chronic health conditions: summary report. Calgary $(\mathrm{AB})$ : Interdisciplinary Chronic Disease Collaboration; 2013:6.

5. Tamblyn R, Laprise R, Hanley JA, et al. Adverse events associated with prescription drug cost-sharing among poor and elderly persons. JAMA 2001;285:421-9.

6. Gagnon M, Hébert G. The economic case for universal pharmacare. Ottawa (ON): Canadian Centre for Policy Alternatives; 2010.

7. Generic drugs in Canada: international price comparisons and potential cost savings. Ottawa $(\mathrm{ON})$ : Patented Medicine Prices Review Board; 2011. Available: www.pmprb-cepmb.gc.ca /english/view.asp? $x=1562 \&$ mid=1436 (accessed 2012 Jan. 9).

8. Kapur V, Basu K. Drug coverage in Canada: Who is at risk? Health Policy 2005;71:181-93.

9. Demers V, Melo M, Jackevicius C, et al. Comparison of provincial prescription drug plans and the impact on patients' annual drug expenditures. CMAJ 2008;178:405-9.

10. Daw JR, Morgan SG. Stitching the gaps in the Canadian public drug coverage patchwork: a review of provincial pharmacare policy changes from 2000 to 2010. Health Policy 2012;104:19-26.

11. Aaserud M, Dahlgren AT, Kosters JP, et al. Pharmaceutical policies: effects of reference pricing, other pricing, and purchasing policies. Cochrane Database Syst Rev 2006;(2):CD005979.

12. Schneeweiss S. Reference drug programs: effectiveness and policy implications. Health Policy 2007:81:17-28.

13. Anis A, Harvard S, Marra C. Ontario's plunging price-caps on generics: deeper dives may drown some drugs. Open Med 2011;5 e149-52.

14. Government of Alberta. Albertans to benefit from reduced prices for existing generic drugs [press release]. Edmonton (AB): Health and Wellness; 2010. Available: http://alberta.ca/acn /201001/277267697CCF8-C8B8-B2D6-D4419AFAE7D72E85 .html (accessed 2012 Mar. 16).
15. Lunn S. Provinces reach deal to save on 6 generic drugs. Toronto (ON): CBC News; 2013. Available: www.cbc.ca/news/canada /story/2013/01/18/pol-generic-drugs-provinces-wall-ghiz.html (accessed 2013 Jan. 24).

16. Gatesman ML, Smith TJ. The shortage of essential chemotherapy drugs in the United States. N Engl J Med 2011;365:1653-5.

17. Reichert S, Simon T, Halm EA. Physicians' attitudes about prescribing and knowledge of the costs of common medications. Arch Intern Med 2000;160:2799-803.

18. Allan GM, Lexchin J, Wiebe N. Physician awareness of drug cost: a systematic review. PLoS Med 2007;4:e283.

19. Hunt SA, Abraham WT, Chin MH, et al. 2009 focused update incorporated into the ACC/AHA 2005 guidelines for the diagnosis and management of heart failure in adults: a report of the American College of Cardiology Foundation/American Heart Association Task Force on Practice Guidelines developed in collaboration with the International Society for Heart and Lung Transplantation. J Am Coll Cardiol 2009;53:e1-90.

20. Alberta Health and Wellness Drug Benefit List. Edmonton (AB): Alberta Health; 2012.

21. Alexander GC, Casalino LP, Meltzer DO. Patient-physician communication about out-of-pocket costs. JAMA 2003;290: 953-8.

22. Alexander GC, Casalino LP, Tseng CW, et al, Barriers to patient-physician communication about out-of-pocket costs. J Gen Intern Med 2004;19:856-60.

23. Choudhry NK, Rosenthal MB, Milstein A. Assessing the evidence for value-based insurance design. Health Aff (Millwood) 2010;29:1988-94

24. Allan GM, Innes GD. Do family physicians know the costs of medical care? Survey in British Columbia. Can Fam Physician 2004;50:263-70

25. Frazier LM, Brown JT, Divine GW, et al. Can physician education lower the cost of prescription drugs? A prospective, controlled trial. Ann Intern Med 1991;115:116-21.

26. Guterman JJ, Chernof BA, Mares B, et al. Modifying provider behavior: a low-tech approach to pharmaceutical ordering. J Gen Intern Med 2002;17:792-6.

27. McMullin ST, Lonergan TP, Rynearson CS, et al. Impact of an evidence-based computerized decision support system on primary care prescription costs. Ann Fam Med 2004;2:494-8.

28. Fretheim A, Aaserud M, Oxman AD. Rational prescribing in primary care (RaPP): economic evaluation of an intervention to improve professional practice. PLoS Med 2006;3:e216.

29. Romanow RJ. Building on values: the future of health care in Canada. Ottawa (ON): Commission on the Future of Health Care in Canada; 2002

30. Phillips K. Catastrophic drug coverage in Canada. Ottawa (ON): Library of Parliament; 2009.

31. Thomson S, Osborn R, Squires D, et al. International profiles of health care systems, 2012. New York (NY): The Commonwealth Fund; 2012 .

32. Saarto T, Wiffen PJ. Antidepressants for neuropathic pain Cochrane Database Syst Rev 2007;(4):CD005454.

33. Wiffen P, Collins S, McQuay H, et al. Anticonvulsant drugs for acute and chronic pain. Cochrane Database Syst Rev 2005;(3): CD001133.

Affiliations: Departments of Medicine (Tang, Ghali, Manns) and Community Health Sciences (Ghali, Manns), and Centre for Health and Policy Studies (Ghali), University of Calgary, Calgary, Alta.

Contributors: All of the authors contributed to the conception and design of the manuscript. Karen Tang drafted the article and William Ghali and Braden Manns revised it critically for intellectual content. All of the authors approved the final version submitted for publication.

Funding: William Ghali was supported by a Senior Health Scholar Award and Braden Manns by career salary support awards from Alberta Innovates Health Solutions. 